\title{
Composição corporal e crescimento de juvenis de piava alimentados com dietas contendo farinhas de trigo e milho submetidas ao cozimento
}

\author{
Body composition and growth of piava juveniles fed with diets containing corn and wheat \\ flours submitted to the cooking

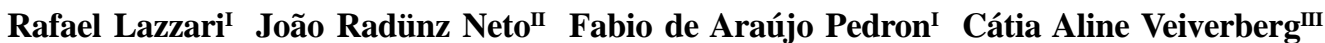

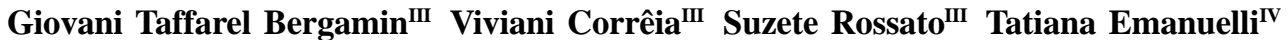 \\ Cristiane Portes Ribeiro ${ }^{\mathrm{IV}}$
}

\begin{abstract}
Neste trabalho, foi avaliado o efeito do cozimento das farinhas de milho e trigo na composição corporal e crescimento de piavas. Foram utilizados 300 juvenis (peso no médio inicial $=8,03 \pm 0,02 \mathrm{~g}$ ), alimentados durante 60 dias, uma vez ao dia $(3 \% \mathrm{PV})$. As dietas utilizadas constituíam-se de matriz única, designadas da seguinte forma: dieta B (sem cozimento), $M$ (farinha de milho cozida), $T$ (farinha de trigo cozida) e dieta MT (ambas as farinhas cozidas). A umidade corporal foi maior nos peixes das dietas $M, T$ e $M T$, ocorrendo o inverso para os lipídios corporais. As cinzas e proteína não apresentaram diferenças significativas. Não se observou efeito do tratamento térmico sobre o crescimento dos peixes. Concluise que o cozimento sobre as farinhas de milho, trigo ou ambas não afeta o crescimento, porém diminui a deposição de lipídios em juvenis de piava.
\end{abstract}

Palavras-chave: piava, carboidratos, cozimento, juvenis, Leporinus obtusidens.

\section{ABSTRACT}

This study was aimed at evaluating the cooking effect in corn and wheat flours in the body composition and growth of piava. They were used 300 juveniles (Initial weight $=8.03 \pm$ $0.02 g)$, fed for 60 days, once a day $(3 \% B W)$. The basal diet was constituted by only matrix, being the treatments designated: diet $B$ (without cooking), $M$ (cooked corn flour), $T$ (cooked wheat flour) and diet MT (both cooked flours). Body moisture was higher in fish fed with $M, T$ and $M T$ diets, while the inverse was observed for the body lipids. The ash and protein values didn't present significant differences. It was not observed effect of the thermal treatment on the fish growth. It's concluded that the cooking in the corn and wheat flours not affect growth, however it reduces lipids deposition in piavas juveniles.

\section{-NOTA-}

Key words: piava, carbohydrates, cooking, juveniles, Leporinus obtusidens.

O aproveitamento dos ingredientes utilizados em dietas pode ser melhorado por técnicas de processamento, como por calor, na qual o amido é gelatinizado, melhorando a digestibilidade do alimento (ALONSO et al., 2000). A gelatinização do amido e de outros tipos de carboidratos presentes em cereais inicia a partir de $70^{\circ} \mathrm{C}$ em presença de umidade (SVIHUS et al., 2005).

A piava (Leporinus obtusidens) é uma espécie nativa das regiões Sul e Sudeste do Brasil, com hábito alimentar onívoro e grande aceitação pelos consumidores (HARTZ et al., 2000). Para pós-larvas desta espécie, verificou-se que a utilização de subprodutos de milho e trigo, como os glutens, proporcionam bom crescimento (FILIPETTO et al., 2005). Em face das escassas informações sobre a nutrição dessa espécie, este trabalho teve por objetivo verificar o efeito do cozimento das farinhas de trigo e milho sobre o crescimento e a composição corporal de juvenis de piava.

Este estudo foi conduzido no Laboratório de Piscicultura (altitude 95m, latitude sul 2943’ e longitude oeste $53^{\circ} 42^{\prime}$ ) da Universidade Federal de Santa Maria. Para tal, 300 juvenis de piava (peso

IPrograma de Pós-graduação em Zootecnia (PPGZ), Universidade Federal de Santa Maria (UFSM), Santa Maria, RS, Brasil.

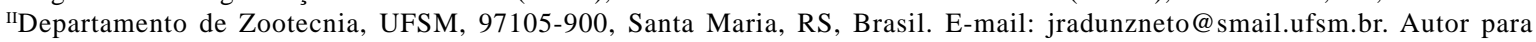
correspondência.

IIICurso de graduação em Zootecnia, UFSM, Santa Maria, Brasil.

${ }^{\text {IV }}$ Departamento de Tecnologia e Ciência dos Alimentos, UFSM, Santa Maria, RS, Brasil. 
inicial $=8,03 \pm 0,02 \mathrm{~g}$ ) foram alimentados durante 60 dias (uma vez ao dia, $3 \% \mathrm{PV}$ ). Os peixes foram distribuídos em dez tanques (350L) de cimento amianto revestido com tinta epóxi, em delineamento inteiramente casualizado, com número variável de repetições (30 juvenis/tanque). Os tratamentos B e MT tiveram duas repetições e os demais três. O sistema de criação utilizado foi de recirculação de água, com temperatura controlada e filtragem biológica. Semanalmente, os parâmetros de qualidade de água foram mensurados com o auxílio de kit colorimétrico (“Alfakit”).

Foram testados quatro tratamentos designados a partir do cozimento das farinhas de milho e/ou trigo. A formulação da ração constituía-se de matriz única (farinha de carne e ossos (8\%), farelo de soja (36\%), glúten de trigo (4,25\%), farinha de milho (26\%), farinha de trigo (18,75\%), óleo de soja (3\%), sal (1\%), vitaminas e minerais(2\%)), na qual os tratamentos foram assim designados: B (sem cozimento - dieta basal), M (farinha de milho cozida), $\mathrm{T}$ (farinha de trigo cozida) e dieta MT (ambas as farinhas cozidas).

No preparo das dietas, os ingredientes foram misturados a seco até completa homogeneização. Dependendo da dieta, a fração correspondente à farinha de trigo e/ou milho foi separada, procedendo-se a um cozimento prévio constituído de mistura com água aquecida $\left(75-80^{\circ} \mathrm{C}\right)$, em quantidade igual às farinhas utilizadas, durante dez minutos. Após isso, a fração correspondente foi misturada aos demais ingredientes, adicionando-se mais água a temperatura ambiente para auxiliar na peletização, realizada em máquina de moer carne. Posteriormente, as dietas foram levadas à estufa de circulação de ar forçado por 24 horas $\left(55^{\circ} \mathrm{C}\right)$ para secagem. Após isso, foram acondicionadas em sacos plásticos e conservadas em refrigeração $\left(-4^{\circ} \mathrm{C}\right)$.

Ao final do experimento, os peixes foram submetidos a jejum de 24 horas, sendo posteriormente medidos, pesados em balança digital (Marte) - 0,001g. Após a biometria, quatro peixes de cada tratamento foram sacrificados através de punção cervical, sendo então homogeneizados e enviados para análise de composição corporal (proteína, lipídios, cinzas e umidade). Os animais para biometria foram previamente anestesiados com trifenóxietanol (0,03\%) e o abate dos peixes foi efetuado de acordo com as normas de ética e bem-estar animal. As cinzas e a umidade foram determinadas através da metodologia das Normas analíticas do INSTITUTO ADOLFO LUTZ (1985). Os lipídios foram determinados pelo método de BLIGHDYER (1959) e a proteína pelo método de KJELDAHL $(\mathrm{N}=6,25)$ (AOAC, 1995).

A avaliação de desempenho dos peixes foi feita através da determinação de: peso (g); comprimento total (cm); taxa de crescimento específico (\%/dia); conversão alimentar aparente; rendimento de carcaça (\%).

Os valores obtidos foram submetidos à análise de variância e, quando significativas, as médias dos tratamentos submetidos ao cozimento foram comparadas à dieta basal pelo teste de Dunnett $(\mathrm{P}<0,05)$, utilizando-se o pacote estatístico "SAS” (1997).

Os parâmetros físico-químicos da água de criação estiveram dentro da faixa adequada para a criação da espécie (ARANA, 2004). Os valores obtidos foram: temperatura $=24,8 \pm 1,8^{\circ} \mathrm{C}$; alcalinidade total $=36,5$ $\pm 6,3 \mathrm{mgCaCO}_{3} ; \mathrm{pH}=7,3 \pm 0,2 ;$ oxigênio dissolvido=6,7 $\pm 0,3$; amônia total $=1,0 \pm 0,05 \mathrm{ppm}$.

Em relação à composição corporal (Tabela 1), não foi verificado efeito do cozimento na quantidade de proteína e cinzas da carcaça. A umidade dos peixes alimentados com as dietas M, T e MT aumentou em relação aos da dieta controle. Com os lipídios, aconteceu o inverso, sendo que os peixes dos tratamentos $\mathrm{M}$, T e MT apresentaram redução em relação aos da dieta B. Esta menor quantidade de lipídios pode estar associada ao melhor aproveitamento das dietas; entretanto, isso não foi observado no crescimento dos peixes. A relação inversamente proporcional entre umidade e lipídios corporais também foi observada para outras espécies, como para a piracanjuba (BORBA et al., 2006) e a truta (GÉLINEAU et al., 2002).

O desempenho das piavas (Tabela 1) não sofreu influência do tratamento térmico empregado nos ingredientes. $\mathrm{O}$ peso final dos peixes variou de $22 \mathrm{a} 23 \mathrm{~g}$, correspondendo a uma TCE média de 2,3\%/dia. Estes valores são superiores aos verificados por RADÜNZ NETO et al. (2006), que, em um mesmo período de alimentação (60 dias), obtiveram TCE de 1,0\%/dia com juvenis de piava com peso inicial similar ao do presente estudo.

Um melhor desempenho das piavas alimentadas com as dietas M, T e MT era esperado, pois alguns trabalhos mostram que o cozimento proporciona maior digestibilidade de carboidratos, melhorando a utilização da proteína e o crescimento (PERES \& OLIVA-TELES, 2002). Isso se justifica po,r que peixes onívoros possuem maior capacidade de digestão de carboidratos, principalmente pela maior atividade da enzima amilase (HEMRE et al., 2002). Porém, essa capacidade é intrínseca à espécie e pode ser afetada pela complexidade, tipo, nível e fonte de carboidrato e pelo tipo de tratamento (NRC, 1993).

A conversão alimentar obtida neste trabalho (1,2-1,3:1) é considerada satisfatória para peixes de hábito alimentar onívoro (SÁ \& FRACALOSSI, 2002). Esses autores salientam que, além da conversão 
Tabela 1- Composição corporal (\%)e parâmetros de desempenho de juvenis de piava alimentados com dietas com e sem cozimento ${ }^{1}$.

\begin{tabular}{|c|c|c|c|c|c|c|}
\hline & $\mathrm{B}$ & M & $\mathrm{T}$ & MT & $\mathrm{P}=$ & $\mathrm{dpr}$ \\
\hline Umidade & 68,6 & $70,2^{*}$ & $70,2^{*}$ & $70,6^{*}$ & 0,002 & 0,19 \\
\hline Proteína & 18,0 & 16,9 & 18,3 & 16,4 & NS & 0,57 \\
\hline Lipídios & 15,2 & $13,8 *$ & $13,8^{*}$ & $13,1^{*}$ & 0,0001 & 0,06 \\
\hline \multirow[t]{2}{*}{ Cinzas } & 1,4 & 1,1 & 1,2 & 1,1 & NS & 0,16 \\
\hline & \multicolumn{6}{|c|}{ Parâmetros zootécnicos } \\
\hline Peso (g) & 23,5 & 22,9 & 22,9 & 23,5 & NS & 1,20 \\
\hline Comprimento total $(\mathrm{cm})$ & 12,8 & 12,5 & 12,6 & 12,9 & NS & 0,35 \\
\hline Taxa de cresc. específico $\left(\%\right.$ dia $\left.^{-1}\right)$ & 2,3 & 2,2 & 2,2 & 2,3 & NS & 0,09 \\
\hline Conversão alimentar aparente & 1,2 & 1,2 & 1,3 & 1,2 & NS & 0,05 \\
\hline Rendimento de carcaça (\%) & 90,0 & 90,8 & 89,0 & 90,0 & NS & 1,29 \\
\hline
\end{tabular}

${ }^{1}$ Dietas: B: basal (sem cozimento); M: cozimento farinha de milho; T: cozimento farinha de trigo;

MT: cozimento das duas farinhas. dpr: desvio padrão residual.

Composição proximal inicial: umidade: 69,71; cinzas: 1,12; proteínas: 17,83; lipídios: 12,77.

Médias seguidas de * apresentam diferença significativa em relação à dieta-controle pelo teste de Dunnett.

alimentar, outras variáveis como eficiência alimentar, taxa de eficiência protéica e ganho em peso também devem ser levadas em consideração para se avaliar uma dieta. Em relação ao rendimento de carcaça, verificaramse valores iguais aos encontrados para esta espécie por RADÜNZ NETO et al. (2006), em torno de 90\%.

O tratamento térmico de ingredientes de origem vegetal, além da melhoria da digestão de carboidratos, pode auxiliar na inativação de fatores antinutricionais (SATOH et al., 1998). Isso é pertinente para a nutrição da piava, pois trabalhos de FILIPETTO et al. (2005) com pós-larvas e de RADÜNZ NETO et al. (2006) com juvenis desta espécie mostraram que o farelo de soja constitui boa fonte de proteína.

Recomendam-se mais estudos sobre a utilização dos carboidratos pela piava, bem como outras formas de processamento que possam aumentar a digestibilidade das dietas. Dessa forma, um possível aumento da utilização de carboidratos pelo peixe pode economizar a utilização da proteína dietária para fins energéticos, otimizando o crescimento e reduzindo o custo da dieta (HEMRE et al., 2002).

Conclui-se que o cozimento $\left(75-80^{\circ} \mathrm{C}\right)$ nas farinhas de milho e/ou trigo não afeta o crescimento, porém afeta a composição corporal de juvenis de piava (Leporinus obtusidens).

\section{AGRADECIMENTOS}

À Fundação de Amparo à Pesquisa do Estado do Rio Grande do Sul (FAPERGS), pelo auxílio financeiro (processo PROCOREDES n. ${ }^{\circ}$ 04/0546.0). À empresa VITAGRI - Indústria, Comércio e Serviços Ltda., pela realização das análises das dietas.

\section{REFERÊNCIAS}

ALONSO, R. et al. Effects of extrusion and traditional processing methods on antinutrients and in vitro digestibility of protein and starch in faba and kidney beans. Food Chemistry, v.68, p.159-165, 2000.

AOAC. (Association of Official Analytical Chemists). Official Methods of Analysis of AOAC. 16.ed. Arlington, Virginia, 1995. 1018p.

ARANA, L.A.V. Princípios químicos de qualidade da água em Aqüicultura: uma revisão para peixes e camarões. 2.ed. Florianópolis, SC: UFSC, 2004. 231p.

BLIGH, E.G.; DYER, W.J. A rapid method of total lipid extraction and purification. Canadian Journal of Biochemistry and Physiology, v.37, n.8, p.911-917, 1959.

BORBA, M.R. et al. Dietary energy requirement of piracanjuba fingerlings, Brycon orbignyanus, and relative utilization of dietary carbohydrate and lipid. Aquaculture Nutrition, v.12, 183-191, 2006.

FILIPETTO, J.E.S. et al. Substituição de fígado bovino por glúten de milho, glúten de trigo e farelo de soja em rações para pós-larvas de piavas (Leporinus obtusidens). Ciência Rural, v.35, n.01, p.192-197, 2005.

GÉLINEAU, A. et al. The combined effects of feeding time and dietary fat levels on feed intake, growth and body composition in rainbow trout. Aquatic Living Resources, v.15, p.225-230, 2002.

HARTZ, S.M. et al. Alimentação da piava (Leporinus obtusidens) no Lago Guaíba, Porto Alegre, RS, Brasil. Pesquisa Agropecuária Gaúcha, v.6, n.1, p.145-150, 2000.

HEMRE, G.I. et al. Carbohydrates in fish nutrition: effects on growth, glucose metabolism and hepatic enzymes. Aquaculture Nutrition, v.8. p.175-194, 2002.

INSTITUTO ADOLFO LUTZ. Normas analíticas do Instituto Adolfo Lutz. Métodos químicos e físicos para análise de alimentos. São Paulo, 1985. V.1. 368p. 
NRC (National Research Council). Nutrient requirements of fish. Washington, DC: National Academy, 1993. 104p.

PERES, H.; OLIVA-TELES, A. Utilization of raw and gelatinized starch by European Sea bass (Dicentrarchus labrax) juveniles. Aquaculture, v.205, p.287-299, 2002.

RADÜNZ NETO, J. et al. Alimentação da piava (Leporinus obtusidens) com diferentes fontes protéicas. Ciência Rural, v.36, n.5, p.1611-1616, 2006.

SÁ, M.V.C.; FRACALOSSI, D.M. Exigência proteica e relação proteína/energia para alevinos de piracanjuba (Brycon orbignyanus). Revista Brasileira de Zootecnia, v.31, n.1, p.1-10, 2002.

SAS. Statistical Analisys System. User's guide. Version 6.08. 4.Ed. North Caroline, 1997. 846p.

SATOH, S. et al. Effect of extrusion processing on the nutritive value of canola meal for chinook salmon (Oncorhynchus tshawytscha) in seawater. Aquaculture Nutrition, v.4, p.115122, 1998.

SVIHUS, B. et al. Effect of starch granule structure, associated components and processing on nutritive value of cereal starch: a review. Animal Feed Science and Technology, v.122, p.303-320, 2005. 